expressed as counts/min. per mgm. of carbon (Table 1). In the case of neuraminic acid, the carbon-14 activity has been corrected to eliminate the isotope dilution due to the methoxy carbon atom. In the case of the hexosamines, the carbon-14 activity represents that of the free hexosamine.

The results appear to support the thesis that the carbon atoms of glucose contribute directly to the biosynthesis of neuraminic acid, but do not warrant any conclusions as to the mechanism of biosynthesis. Since the injected glucose-14C was diluted by the rat's glucose pool, which has been reported to be $130 \mathrm{mgm}$. per $100 \mathrm{gm}$. of rat tissue $\theta^{6}$, it can be estimated that the isotope concentration in neuraminic acid has undergone a dilution of less than one hundred-fold. The extent of this dilution is interpreted as being indicative of a direct contribution of glucose carbon atoms to the biosynthesis of neuraminic acid.

A comparison of the specific carbon-14 activity of neuraminic acid with that of glucosamine and galactosamine shows that the isotope concentration of glucosamine approaches that of neuraminic acid but is less than that of galactosamine by a factor of 1.7. Although the pool-sizes of some of the intermediates as well as the rates of turnover are unknown at present, it seems reasonable to postulate that glucosamine is not a likely precursor of neuraminic acid, but that galactosamine could conceivably function in such a capacity.

This work was supported, in part, by a grant from the United States Atomic Energy Commission.

\section{KaRI LAUENSTEIN*}

KURT I. AltMaN

Department of Experimental Radiology,

University of Rochester School of Medicine and Dentistry,

Rochester, New York.

$$
\text { May } 29 .
$$

* Max Kade Fellow.

${ }^{1}$ Klenk, E., and Lauenstein, K., Z. physiol. Chem., 291, 147 (1952).

${ }^{2}$ Heimer, R., and Meyer, K., Fed. Proc., 15, 272 (1956).

${ }^{2}$ Gottschalk, A., Yale J. Biol. Med., 28, 525 (1956).

4 Klenk, E., Faillard, H., and Lempfrid, H., Z. physiol. Chem., 301. 235 (1955).

${ }^{5}$ Gardell, S., Acta Chem. Scand., 7, 207 (1953).

- Feller, D. D.. Strisower, E. H., and Chaikoff, I. L., J. Biol. Chem. 187, 571 (1950)

\section{Separation of Steroid Conjugates by Paper Electrophoresis}

THE application of the principle of electrophoretic separation on paper to steroids is limited by their relatively low polarity, so that they do not readily migrate under the influence of an electric current, and also by their sparing solubility in aqueous media. By converting the steroids into derivatives with polar groupings, some separation has been achieved (Voigt and Beckmann ${ }^{1}$, 1953, using the hemisuccinates; McKinley', 1955, using the mono- and di-phenylhydrazone derivatives). Our early experiments, begun before the publication of these authors' results, were along similar lines, and with somewhat similar results. It did not seem likely, however, that electrophoretic separation would be so convenient a method as chromatography, which has been adapted by Lembart and Schneider ${ }^{3}$ for the separation on paper of mixtures of pure steroid conjugates. The natural occurrence of more polar steroid derivatives, the sulphates and glucuronides in urine, suggested to us that these might undergo electrophoretic separation on paper. Although the individual steroids could not be resolved, the two groups of conjugates were sharply separated.

The apparatus used was a simple box type, accommodating the paper strips horizontally. Of several systems tried, a veronal buffer solution of ionic strength $0 \cdot 1$ and $p H \quad 8 \cdot 6$ containing 20 per cent ethanol was found to give the best results. Whatman No. 31 filter paper was used, and a potential difference of 240 volts and a current strength of $0.5 \mathrm{~m}$.amp. per $\mathrm{cm}$. of paper was applied for $16 \mathrm{hr}$. A mixture of dehydroisoandrosterone and its sulphate subjected to electrophoresis under these conditions showed that the steroid sulphate travelled $11 \mathrm{~cm}$. towards the anode while the free steroid had moved slightly towards the cathode. An extract containing both the free and conjugated steroids was obtained from urine by half saturation with ammonium sulphate followed by extraction with an ether-alcohol mixture. An amount of extract containing approximately 200 micrograms of total steroid was used for separation. After drying, the paper strip was treated with Zimmermann reagent. Two violet bands were obtained, both on the anode side of the point of application, the glucuronide fraction varying from 5 to $7 \mathrm{~cm}$., and the sulphate from 8 to $10 \mathrm{~cm}$. from the initial line. In addition, a very small amount of free steroid was found at, and slightly to the cathode side of, the starting point. A number of bands due to other non-steroid urinary constituents were also present; for example, a brown band of urea was always seen at about $1 \mathrm{~cm}$. on the cathode side.

In addition to experiments on mixtures of known steroids, further evidence suggesting the composition of the two fractions was given by showing that the glucuronide fraction was almost completely removed by previous treatment of the urine with glucuronidase before extraction, and by demonstrating the virtual absence of glucuronic acid in the sulphate fraction. The fractions can also be quantitatively estimated after elution from an unstained strip, and this has been carried out both for normal and pathological urines and for blood. Table 1 shows the results from a normal adult urine, as an example.

Table 1

\begin{tabular}{|c|c|c|c|c|}
\hline & $\begin{array}{c}\text { Amount } \\
\text { applied }\end{array}$ & $\begin{array}{c}\text { Free } \\
\text { steroids }\end{array}$ & Sulphates & Glucuronides \\
\cline { 2 - 4 } & $140 \mu \mathrm{gm}$. & $3 \mu \mathrm{gm}$. & $37 \mathrm{gm}$. & $99 \mu \mathrm{gm}$. \\
$\begin{array}{c}17-\text { ketosteroids } \\
\text { corticosteroids }\end{array}$ & $88 \mu \mathrm{gm}$. & $2 \mu \mathrm{gm}$. & $6 \mathrm{gm}$. & $82 \mu \mathrm{gm}$. \\
\hline
\end{tabular}

Besides affording a simple means of estimating the proportions of steroid sulphates and glucuronides in urine and blood, for which, so far as we know, there is no direct method, the procedure can also be applied for purifying the fractions prior to hydrolysis and subsequent identification of the components, and also for preparative purposes. Work along these lines is actively proceeding, and fuller details of the method and its applications will be published elsewhere.

\section{B. LEVIN}

G. DAviES

Department of Pathology,

Queen Elizabeth Hospital for Children,

Hackney Road, London, E.2. July 21.

2 Voigt, K. D., and Beckmann, I., Acta Endocrinol., 13, 19 (1953).

${ }^{2}$ McKinley, W. P., Science, 121, 139 (1955).

${ }^{3}$ Lembart, N. I., and Schneider, J. J., Nature, 176, 1175 (1955). 